\title{
Sociodemographic, Rationale Drug Use of Antiepileptic Drugs among Pediatric Patients with Epilepsy: A Prospective Study at a Tertiary Care Hospital
}

\author{
S. Dwajani ${ }^{1} \quad$ E. Adarsh ${ }^{2} \quad$ K. S. Nirmala ${ }^{3} \quad$ H. Sahajananda ${ }^{4}$
}

${ }^{1}$ Department of Pharmacology and Central Research laboratory, Rajarajeswari Medical College and Hospital, Bengaluru, Karnataka, India

2Department of Pediatrics, Rajarajeswari Medical College and Hospital, Bengaluru, Karnataka, India

${ }^{3}$ Central Research Laboratory, Rajarajeswari Medical College and Hospital, Bengaluru, Karnataka, India

${ }^{4}$ Department of Anaesthesia and Central Research laboratory,

Rajarajeswari Medical College and Hospital, Bengaluru, Karnataka, India

\author{
Address for correspondence S. Dwajani, PhD, Department \\ of Pharmacology, Central Research Laboratory, Rajarajeswari \\ Medical College and Hospital, Bengaluru 560 074, Karnataka, India \\ (e-mail: dwajani@gmail.com).
}

J Neurosci Rural Pract 2019;10:474-478

\begin{abstract}
Background Drug utilization studies are important and considered as a potential tool for the evaluation of health care systems. The goal of drug utilization research studies should be to assess whether drug therapy is rational or not.

Objective The main aim of this article is to analyze the different types of epilepsy and their drug utilization pattern in children with epilepsy at the Department of Pediatrics and evaluate the extent of older and newer antiepileptic drugs (AEDs), either as monotherapy or polytherapy in pediatric age groups.

Materials and Methods To look into the sociodemographic profile of children with epilepsy, the type of epilepsy was diagnosed along with drug utilization pattern in children attending both outpatient and inpatient department of pediatrics. Demographic details were collected according to modified Kuppuswamy scale. Disease characteristics such as type of epilepsy, onset, duration, time since last attack, family history, comorbid conditions, monotherapy/polytherapy, dose, and duration of treatment were noted. Investigations such as electroencephalography, magnetic resonance imaging, and computed tomographic scan if any were recorded.

Results In this pilot study, we have 100 patients, younger than 18 years, with confirmed cases of epilepsy, receiving AEDs either monotherapy or polytherapy. Male predominance was $56 \%$, and $60 \%$ were from rural areas and $40 \%$ were from urban areas. As per the modified Kuppuswamy scale, we analyzed socioeconomic class of these 100 patients and found that $40 \%$ belong to lower-middle-class family. Nearly $51 \%$ were diagnosed with generalized tonic clonic seizures, $30 \%$ were with febrile seizures, while focal, partial, absence, and myoclonic seizures, and hot water epilepsy were less in percentage. Almost $83 \%$ received monotherapy, while only $17 \%$ received polytherapy.

\section{Keywords}

- antiepileptic drugs

- epilepsy monotherapy

- polytherapy

Among monotherapy, $51.80 \%$ received older AEDs and $48.20 \%$ received newer drugs.

Conclusion Although epilepsy can be controlled and managed effectively with older AEDs, an experience in management with newer AEDs is required to offer an additional advantage to patients to have better safety profile.
\end{abstract}

DOI https://doi.org/

$10.1055 / \mathrm{s}-0039-1698280$

ISSN 0976-3147.
C2019 Association for Helping

Neurosurgical Sick People
License terms

(ㄷ) (1) $\ominus \circledast$ 


\section{Introduction}

Drug utilization studies are important and considered a potential tool for evaluation and assessment of health care systems. They are powerful exploratory tools to ascertain the role of the drugs in our society. ${ }^{1}$ Drug utilization study is an essential part of pharmacoepidemiology and is defined as "marketing, distribution, prescription and use of drugs in society with specific emphasis on resulting medical, social and economic consequences." 2 The ultimate goal of drug utilization research is to assess whether drug therapy is rational or not. ${ }^{3}$

It is important to develop a twin concept of therapeutic formulation and essential drugs list, which is considered to be the main reason for studying drug utilization. ${ }^{4}$ Hence, it becomes important in establishing a selected list of drugs, which needs to be guided to an important extent not just by epidemiological statistics and scientific considerations toward efficacy and safety, but also by the present pattern of treatment. Therefore, the mainstay in the management of epilepsy is antiepileptic drugs (AEDs). The comparison between the conventional and newer drugs with regard to their beneficial effects is still under debate. Treatment of epilepsy in children or adults is either by monotherapy or by combination of AEDs. Treatment with AEDs should be aimed and focused in such a way that controlling seizures with lesser side effects, possibly with monotherapy, allows the child to contribute actively to the society with cost-effective treatment. Childhood epilepsy remains a challenge to treat; despite an increase in the number of AEDs, children continue to have seizures. ${ }^{2}$

Hence, we decided to look into the sociodemographic profile of these children with epilepsy and type of epilepsy diagnosed along with drug utilization pattern in children attending both outpatient and inpatient departments of pediatrics. We like to consider this as a pilot study, as our further goal is to form a registry for pediatric epilepsy cases.

\section{Materials and Methods}

The study was conducted in a tertiary care hospital in Bengaluru, Karnataka, India, after obtaining ethical committee clearance. This was a prospective, observational study, in which the data were recorded in a register, and was considered as pilot study with an aim to continue as registry in large number of populations. In this pilot study, we have 100 patients, who attended outpatient and inpatient departments of pediatrics. Children younger than 18 years, with confirmed cases of epilepsy, receiving AEDs either monotherapy or polytherapy, were enrolled in the study only after obtaining consent from the parents or the legal guardians.

Data were entered in a register where demographic details were collected according to the modified Kuppuswamy scale. Disease characteristics such as type of epilepsy, onset and duration, time since last attack, frequency, family history of epilepsy, and comorbid conditions were also recorded. Treatment details such as monotherapy/polytherapy, dose, and duration of treatment were noted. Investigations such as electroencephalography (EEG), magnetic resonance imaging, and computed tomographic scan if any were recorded.

\section{Results}

A total of 100 patients were included in the pilot study. There was a male predominance (male children $56 \%$, female children $44 \%$ ). The majority of patients were in the age group of 1 to 5 years (42\%), with male preponderance $(61.90 \%)$, followed by 6 to 10 years (29\%) of age ( - Fig. 1 ).

Among the 100 patients, $60 \%$ were from rural background and $40 \%$ were from urban background, while majority had completed their high school (31\%) and 33\% were under the category of clerk or were shop owners. As per the modified Kuppuswamy scale, ${ }^{5}$ we analyzed the socioeconomic class of these 100 patients, and we found that $40 \%$ belong to lower-middle-class family (-Table 1).

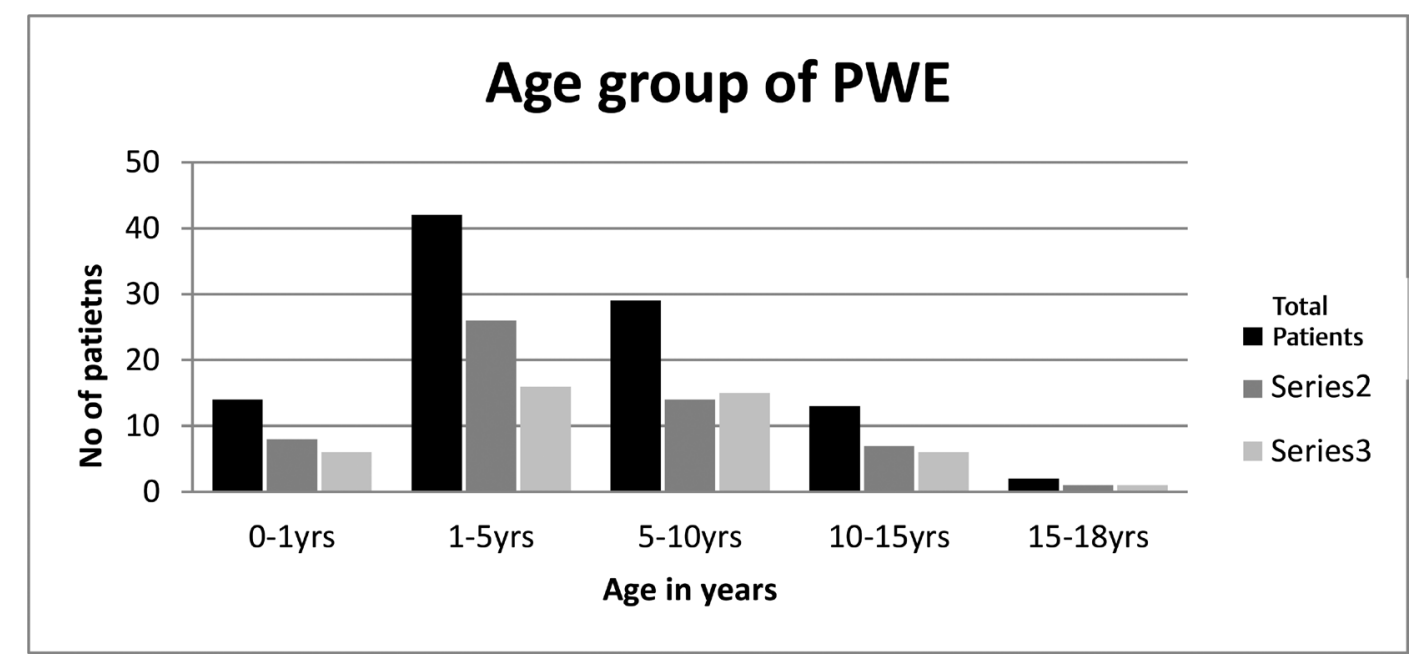

Fig. 1 Distribution of patients according to age. PWE, patient with epilepsy. 
On assessing the family history of seizures, $42 \%$ of patients reported with positive cases of epilepsy on treatment/being treated, within their near/dear family members. With regard to the initiation of treatment, $56 \%$ of patients began treatment with AEDs immediately within 3 months of attack

Table 1 Sociodemographic data of patients with epilepsy

\begin{tabular}{|c|c|}
\hline Sociodemographic data & Percentage \\
\hline \multicolumn{2}{|l|}{ Education of head of the family } \\
\hline Illiterate & 23 \\
\hline Primary school & 6 \\
\hline Middle school & 10 \\
\hline High school & 31 \\
\hline Intermediate school & 12 \\
\hline Graduate and PUC & 17 \\
\hline Professional and honor & 1 \\
\hline \multicolumn{2}{|l|}{ Occupation of head of the family } \\
\hline Unemployed & 0 \\
\hline Unskilled & 23 \\
\hline Semiskilled & 7 \\
\hline Skilled & 32 \\
\hline Clerical, shop owner & 33 \\
\hline Semiprofessional & 5 \\
\hline Profession & 0 \\
\hline \multicolumn{2}{|l|}{$\begin{array}{l}\text { Socioeconomic class as per the modified } \\
\text { Kuppuswamy scale }\end{array}$} \\
\hline Upper class & 0 \\
\hline Upper middle class & 22 \\
\hline Lower middle class & 40 \\
\hline Upper lower class & 38 \\
\hline Lower class & 0 \\
\hline
\end{tabular}

Abbreviation: PUC, pre-university course.
(-Table 2). That is, the patient was brought to the hospital soon after the attack.

EEG was done as a diagnostic tool in all the 100 patients, where $40 \%$ patients had abnormal EEG findings. Among these 100 pediatric patients, majority (51\%) were diagnosed with generalized tonic clonic seizures (GTCS) followed by febrile seizures (30\%); focal seizures; partial, absence, and myoclonic seizures; and hot water epilepsy, which were less in percentage. Other types of seizures include hypoglycemic seizures $(n=1)$ and abdominal seizures $(n=1)$ (-Fig. 2 ).

With regard to the treatment with AEDs, the majority of the patients (83\%) received monotherapy, while only $17 \%$ received polytherapy. Among patients who received monotherapy, $51.80 \%$ received older AEDs and $48.20 \%$ received newer drugs (-Fig. 3). Among polytherapy, all patients received two drug combinations with older or with older + newer AEDs (- Table 3 ).

\section{Discussion}

Childhood epilepsy results in potential impeding on education, social relation, and development of sense of being worthless. Diagnosis with prompt and appropriate treatment with AEDs will optimize the seizures. Drug therapy with AEDs is the mainstay of epilepsy treatment. The major goal in treatment with AEDs is to minimize the frequency of seizures and to reduce the side effects. This becomes important

Table 2 Time taken to initiate antiepileptic drugs treatment after the first attack of seizure

\begin{tabular}{|l|l|}
\hline Time duration & Percentage \\
\hline With 3 mo of the attack & 56 \\
\hline 4 mo -1 y of attack & 20 \\
\hline $1-2$ y of attack & 3 \\
\hline $2-3$ y of attack & 4 \\
\hline$>3$ y & 17 \\
\hline
\end{tabular}

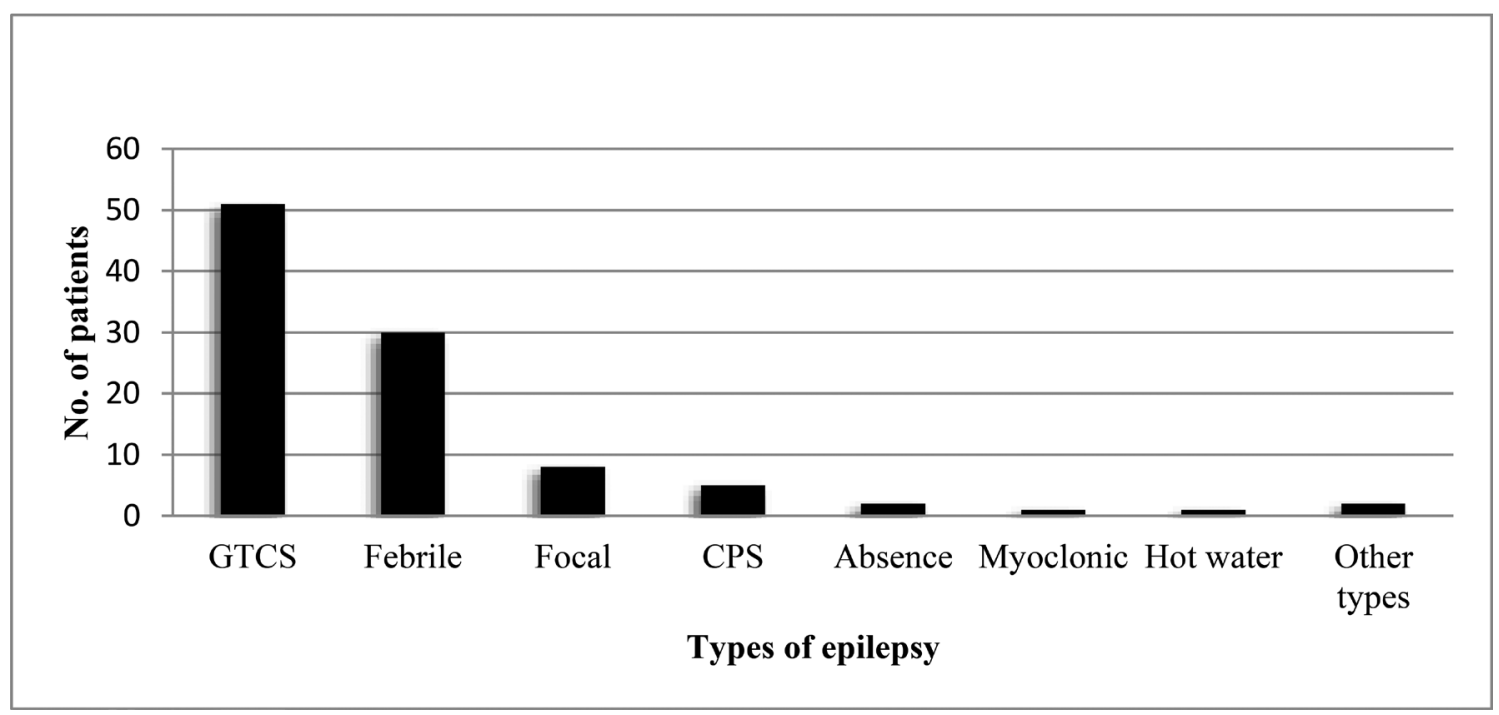

Fig. 2 Type of seizures in pediatric patients with epilepsy. CPS, complex partial seizure; GTCS, generalized tonic clonic seizures; PWE, patient with epilepsy. 


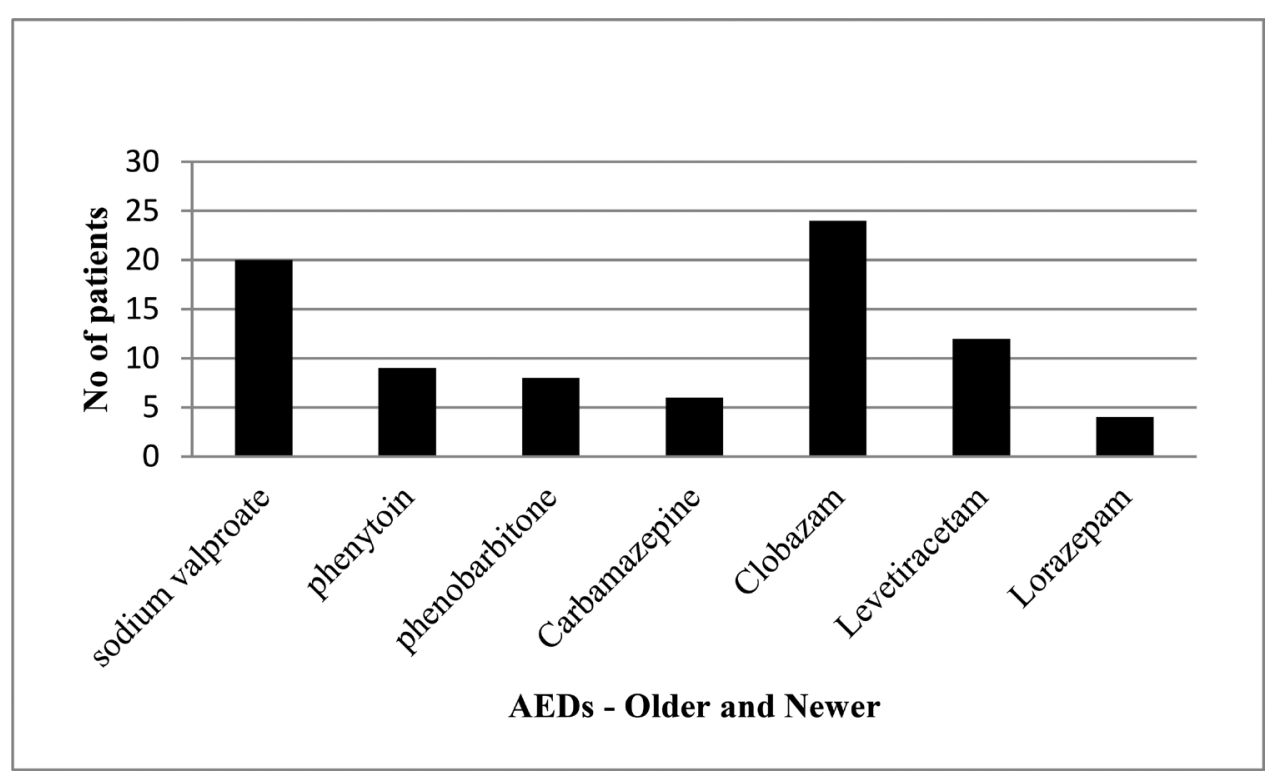

Fig. 3 Treatment pattern of antiepileptic drugs in pediatric patients with epilepsy receiving monotherapy. AEDs, antiepileptic drugs; PWE, patient with epilepsy.

Table 3 Polytherapy drugs received in pediatric patients with epilepsy

\begin{tabular}{|l|l|}
\hline Polytherapy AED combination received $(\boldsymbol{n}=17)$ & $n(\%)$ \\
\hline Phenobarbitone + clobazam & $2(11.76)$ \\
\hline Sodium valproate + levetiracetam & $2(11.76)$ \\
\hline Phenobarbitone + levetiracetam & $3(17.64)$ \\
\hline Phenytoin + levetiracetam & $1(5.88)$ \\
\hline Sodium valproate + topiramate & $1(5.88)$ \\
\hline Phenytoin + clobazam & $2(11.76)$ \\
\hline Phenobarbitone + clobazam & $1(5.88)$ \\
\hline Sodium valproate + clobazam & $3(17.64)$ \\
\hline Levetiracetam + clobazam & $2(11.76)$ \\
\hline
\end{tabular}

Abbreviation: AED, antiepileptic drug.

because pediatric patients differ anatomically and physiologically from normal healthy adults with regard to weight and surface area. The physiological systems in pediatric patients are in growing phase, which contribute to change in pharmacokinetic and pharmacodynamic effects. ${ }^{4}$

In our study, a majority of patients receiving AEDs were male and belonged to age group between 1 and 5 years, which is similar to the study done by Bhatt et $\mathrm{al}^{3}$ as well as Maity and Gangadhar. ${ }^{4}$ As per the modified Kuppuswamy scale, we found that $40 \%$ belong to lower-middle-class family and had started the treatment immediately after an attack. This could be because of the education, better financial status, and knowledge about epilepsy among parents of children with epilepsy, while $17 \%$ of patients were treated only after 3 years of the first attack which could be due to social stigma, lower financial background, and myths and misconceptions among the parents of children with epilepsy. Socioeconomic status, mainly the income, plays a very important role in the quality of life among patients with epilepsy as reported by Nagarathnam et al. ${ }^{6}$
Positive family history of seizures was found in $46 \%$ of patients. It has been reported in the previous study that epilepsy is a hereditary disorder; family history and genetic predisposition lead to an increased risk of seizure in children. ${ }^{7}$ The majority (i.e., 56\%) of patients had no specific cause for seizure, which was similar to the study by Hanssens et $\mathrm{al}^{8}$ conducted in 2002. EEG was done in all the 100 pediatric patients, with epilepsy considered as the diagnostic tool. As per the American Academy of Neurology guidelines for epilepsy, EEG is recommended as a part of routine neurodiagnostic evaluation for the diagnosis of epilepsy. ${ }^{9}$

An International League Against Epilepsy classification of epilepsy and epileptic syndromes is useful for the diagnosis and management of epilepsy. The majority (51\%) had GTCS, followed by $30 \%$ of focal seizures. In this study and in other study conducted at Oman by Hanssens et al, ${ }^{8}$ it was summarized that GTCS was the major type of epilepsy, while in contradiction, two different studies conducted in Malaysia and Sweden by Hasan $^{10}$ and Larsson, ${ }^{11}$ respectively, showed that focal seizures were in majority, which could be due to racial, ethnic, or genetic difference of various regions. With regard to the treatment of epilepsy, sodium valproate monotherapy was the most common AED prescribed (24.09\%), which is similar to the study from the United Kingdom (22\%) conducted by Moran et al. ${ }^{12}$ In comparison to other studies, carbamazepine was the most common drug followed by sodium valproate, ${ }^{13-16}$ while in a study conducted in European and Asian countries, sodium valproate was the least prescribed AED. ${ }^{16,17}$ As per the National Institute of Clinical Excellence (NICE) guidelines, it has been advised that either sodium valproate or carbamazepine should be considered as the first line of therapy for epilepsy. If in case there is no control with one drug, alternative monotherapy with other AEDs should be tried before considering polytherapy. In the recent trends, shifting of prescription pattern to these older drugs, that is, sodium valproate and carbamazepine from phenobarbitone and phenytoin, could be due to better safety profile. 
The newer AEDs are not being recommended as first-line drugs owing to limited clinical experience and cost, while the use of these drugs is reserved for such epileptic patients who do not respond to older AEDs. The NICE guidelines report that the role of newer AEDs as first-line monotherapy will come into action only when randomized clinical trials can prove their efficacy role in comparison to older AEDs. In our study, levetiracetam was the most commonly used AED in contrast to lamotrigine and oxcarbazepine being prescribed commonly in a study conducted by Maity and Gangadhar ${ }^{4}$ and Bhatt et $\mathrm{al}^{3}{ }^{3}$ respectively. Clobazam was the second widely used drug among newer AEDs for febrile seizure reported in $30 \%$ of cases in our study. Comparing to a study conducted by Gupta, ${ }^{18}$ it was reported that children younger than 12 months, diagnosed with febrile seizures, may have $50 \%$ chances of recurrent febrile seizures, which is considered as the most common type of seizure among children. The present study has indicated that monotherapy is the modality of treatment, which is used frequently in all types of seizures. Monotherapy is preferred over polytherapy because of low-cost, better safety profile with lesser side effects and undesirable drug interactions. This also helps in improving medication compliance and adherence because of simplified drug administration. Only in those patients in whom single drug therapy does not control seizures effectively, polytherapy may be necessary as better treatment goal. Monotherapy is considered as gold standard for treatment of epilepsy, which is effective in 44 to $79 \%$ of patients, ${ }^{19-21}$ and this study proves in accordance with it.

\section{Conclusion}

A national-based study and guidelines will help us to bring more rational approach for AED therapy. Very few studies have been conducted on childhood epilepsies and are compared with different treatment options or to prove certain guidance concerning treatment strategies. Although epilepsy can be controlled and managed effectively with older AEDs, an experience in management with newer AEDS is required to offer an additional advantage to patients to have better safety profile. Hence, this study helps in evaluating the existing drug use pattern and rationality of prescription, while most of the prescription was as per the NICE guidelines. Our study had a limitation of smaller sample size, as this was considered to be a pilot study. Further to this, a registry study is being conducted at our hospital, with larger sample size for better assessment of rational drug prescribing.

\section{Funding \\ None.}

\section{Conflict of Interest}

None declared.

\section{References}

1 Shalini S, Ravichandran V, Mohanty BK, Dhanaraj SK, Saraswathi R. Drug utilization studies-An overview. Int J Pharm Sci Nanotechnol 2010;3:803-810
2 Mistry RA, Solanki KC, Prajapathi HK, Doshi TM, Trivedi HR. Drug utilization pattern of antiseizure drugs and their adverse effects in the pediatric population, in a tertiary care hospital attached to medical college. Int J Basic Clin Pharmacol 2014;3:336-343

3 Bhatt KM, Malhotra SD, Patel KP, Patel VJ. Drug utilization in pediatric neurology outpatient department: a prospective study at a tertiary care teaching hospital. J Basic Clin Pharm 2014;5(3):68-73

4 Maity N, Gangadhar N. Trends in utilization of antiepileptic drugs among pediatric patients in a tertiary care hospital. Curr Neurobiol 2011;2:117-123

5 Singh T, Sharma S, Nagesh S. Socio-economic status scales updated for 2017. Int J Res Med Sci 2017;5:3264-3267

6 Nagarathnam M, Vengamma B, Latheef SA, Reddemma K. Assessment of quality of life in epilepsy in Andhra Pradesh. Neurol Asia 2014;19:249-255

7 Michel VJ. Seizures in childhood. In: Robert MK, Richard EB, Hal BJ, Bonita FS, eds. Nelson Textbook of Pediatrics. 18th edition. New Delhi, India: Saunders Elsevier; 2007 2457-2473

8 Hanssens Y, Deleu D, Al Balushi K, Al Hashar A, Al-Zakwani I. Drug utilization pattern of anti-epileptic drugs: a pharmacoepidemiologic study in Oman. J Clin Pharm Ther 2002;27(5):357-364

9 Krumholz A, Wiebe S, Gronseth G, et al. Quality Standards Subcommittee of the American Academy of Neurology; American Epilepsy Society. Practice parameter: evaluating an apparent unprovoked first seizure in adults (an evidence-based review): report of the Quality Standards Subcommittee of the American Academy of Neurology and the American Epilepsy Society. Neurology 2007;69(21):1996-2007

10 Hasan SS, Bahari MB, Babar ZU, Ganesan V. Antiepileptic drug utilisation and seizure outcome among paediatric patients in a Malaysian public hospital. Singapore Med J 2010;51(1):21-27

11 Larsson K, Eeg-Olofsson O. A population based study of epilepsy in children from a Swedish county. Eur J Paediatr Neurol 2006;10(3):107-113

12 Moran NF, Poole K, Bell G, et al. Epilepsy in the United Kingdom: seizure frequency and severity, anti-epileptic drug utilization and impact on life in 1652 people with epilepsy. Seizure 2004;13(6):425-433

13 Peichev L, Marazova K. Epidemiological study of the frequency of prescribing antiepileptic drugs. Folia Med (Plovdiv) 1992;34(3/4):8-13

14 Muir TM, Bradley A, Wood SF, Murray GD, Brodie MJ; West of Scotland Epilepsy Research Group. An audit of treated epilepsy in Glasgow. Seizure 1996;5(1):41-46

15 Olafsson E, Hauser WA. Prevalence of epilepsy in rural Iceland: a population-based study. Epilepsia 1999;40(11):1529-1534

16 Kuruvilla A, Prabakar S. Utilization pattern of drugs in epilepsy and factors influencing reactions to commonly prescribed drugs-a study in South Indian patients. Indian J Pharmacol 1993;25:83-87

17 Oun A, Haldre S, Mägi M. Use of antiepileptic drugs in Estonia: an epidemiologic study of adult epilepsy. Eur J Neurol 2006;13(5):465-470

18 Gupta S. Febrile seizures-an overview and use of clobazam as intermittent therapy. Pediatr Today 2002;5:113-118

19 Chen LC, Chen YF, Yang LL, Chou MH, Lin MF. Drug utilization pattern of antiepileptic drugs and traditional Chinese medicines in a general hospital in Taiwan-a pharmaco-epidemiologic study. J Clin Pharm Ther 2000;25(2):125-129

20 Deckers CL. Overtreatment in adults with epilepsy. Epilepsy Res 2002;52(1):43-52

21 Kwan P, Brodie MJ. Effectiveness of first antiepileptic drug. Epilepsia 2001;42(10):1255-1260 